\title{
NEOLIBERALISMO E (SEMI) FORMAÇÃO: COMPETÊNCIA E PRODUTIVIDADE PARA A EDUCAÇÃO?
}

\author{
Ademir Henrique Manfré \\ Universidade do Oeste Paulista - UNOESTE, Faculdade de Artes, Ciências, Letras e Educação - FACLEPP, Presidente \\ Prudente, SP. E-mail: ademirmanfre@yahoo.com.br.
}

\section{RESUMO}

Este artigo insere-se na temática Políticas Públicas, Educação e Currículo Escolar. É resultado de pesquisas e debates realizados durante o 20 semestre de 2016 e 10 semestre de 2017 junto aos cursos de licenciatura de uma faculdade do interior do estado de São Paulo. Tem como objetivo geral apresentar e questionar a temática das reformas educacionais atuais mediadas pelas políticas neoliberais, evidenciando a fragilidade das referidas com relação à proposta de formação cultural (Bildung). O caminho trilhado para essa investigação consistiu na análise interpretativa e em estudos teóricos indicados pela área específica, na análise e problematização de textos e autores, tais como Santana (2017), Larrosa (2002), Adorno (1996) e Benjamin sobre o depauperamento do pensar na escola mediada pela racionalidade instrumental e tecnificada. A questão norteadora dessa análise é a seguinte: qual o lugar da experiência no ensino? Dessa forma, essa reflexão pretende abrir uma discussão crítica sobre formação de professores, Educação, Currículo Escolar e experiência formativa, fomentando a possibilidade de resistência à semiformação e aos aspectos semiculturais das (contra) reformas educacionais.

Palavras-chave: Educação. Experiência (Erfahrung). Semiformação (Halbbildung). Formação de professores.

\section{DO NEOLIBERALISM AND (SEMI) FORMATION PROMOTE COMPETENCE AND PRODUCTIVITY FOR EDUCATION?}

\begin{abstract}
This article is part of the Public Policy, Education, and School Curriculum topics. It is the result of researches and debates held during the second semester of 2016 and the first semester of 2017 within the Undergraduate Courses of a University in the interior of the State of São Paulo. Our aim was to present and questioning the topic of current educational reforms proposed by neoliberal policies, highlighting their fragility in relation to the proposal of cultural formation (Bildung). The path of this research consisted of interpretive analysis and theoretical studies indicated by the specific area, in the analysis and problematization of texts and authors, such as Santana (2017), Larrosa (2002), Adorno (1996), and Benjamin on the impoverishment of thinking at school mediated by instrumental and technified rationality. The main question of our analysis can be stated as follows: What is the place of experience in teaching? Thus, this reflection intends to open a critical discussion about teacher training, Education, School Curriculum and formative experience, fomenting the possibility of resistance to semiformation and semicultural aspects of educational (counter) reforms.
\end{abstract}

Keywords: Education. Experience (Erfahrung). Semiformation (Halbbildung). Teacher's training. 


\section{INTRODUÇÃO}

Este artigo trata da temática Políticas Públicas, Currículo Escolar e Educação. A partir de pesquisas realizadas junto à disciplina "Currículo e Escola" oferecida pelo curso de licenciatura em Pedagogia da FACLEPP/UNOESTE, pretendemos realizar um debate crítico sobre as (contra) reformas educacionais impostas pelo governo federal.

Diante do assinalado, a escola tem sido convocada a cumprir a função de transformar a realidade do país, buscando o desenvolvimento econômico. Os parâmetros dessas políticas são as diretrizes internacionais provenientes dos organismos financeiros, como o Banco Mundial e o FMI.

Sob essa perspectiva, as reformas educacionais postulam a necessidade de adequação do trabalho pedagógico às novas demandas oriundas do mundo do trabalho e da sociedade da informação. De que modo isso ocorre?

O Estado Neoliberal tem intervindo na Educação com uma política de adequação da profissão docente pautada pelos interesses mercantilistas.

A partir do exposto, as políticas públicas de formação de professores ancoram-se nesse contexto de (re) formulações, uma vez que lançam aos profissionais da Educação novos desafios.

Oliveira (2003) aponta que a formação atual requerida pelos organismos internacionais pauta-se pelas noções de competências e habilidades. A autora justifica que, um novo tipo de Estado - o Estado Neoliberal ${ }^{1}$ - se tornou necessário para gerenciar os serviços essenciais, como, por exemplo, a Educação.

Outros pensadores do campo das Políticas Públicas educacionais afirmam que a noção de competência surgiu com a Lei de Diretrizes e Bases da Educação Nacional - Lei n. 9394/96, que trata da Educação básica e profissional.

No sentido da investigação proposta, sustentamos a seguinte tese: os modelos formativos atuais são fundamentados, essencialmente, em projetos políticos neoliberais, entendidos como estratégias para o sucesso do modelo mercadológico. As políticas formativas são sustentadas pelo modelo do "aprender a aprender" ${ }^{2}$ constantemente, processo esse desvinculado do aprender a pensar.

Ao atrelar a lógica educacional à do mercado, a primeira saiu perdendo. $\mathrm{Na}$ maioria das vezes, em nome de uma "qualidade total", acontece um controle severo que impede a autonomia dos professores, o que enfraquece a própria comunidade escolar. (SANTANA, 2017, p. 86).

Conforme pontado acima, ao analisarmos as características do contexto educacional sob o enfoque da doutrina neoliberal, notamos que elas não se distanciam dos objetivos requeridos por uma empresa: competitividade, produtividade e inovação, em que "[...] o objetivo dos sistemas de ensino passa a ser atingir metas, o que não significa, necessariamente, um aprendizado, [...] um ensino que o leve ao pensamento crítico". (SANTANA, 2017, p. 86).

Nesse momento de nossa exposição, duas anotações se tornam necessárias. A primeira é que as transformações socioeconômicas exigidas pelo alinhamento do Estado à doutrina neoliberal provocaram novas exigências para as políticas públicas educacionais ${ }^{3}$. A segunda é que a racionalidade instrumental presente nas (contra) reformas educacionais não promovem a reflexão crítica e emancipadora.

\footnotetext{
1 Privatização, Estado mínimo, desregulamentação, flexibilização, terceirização, globalização são as características do neoliberalismo. Essas características também são estendidas para a Educação Escolar, conforme Santana (2017).

${ }^{2}$ Em "Educação: um tesouro a descobrir", coordenado por Jacques Delors (2012), se evidencia as quatro aprendizagens de uma Educação para o século XXI: 1. aprender a conhecer; 2. aprender a fazer; 3. aprender a conviver e 4. aprender a ser. Esses quatro elementos não podem ser vivenciados de forma fragmentada, traduzindo-se como quatro vias de uma formação continuada no processo de aquisição do conhecimento.

${ }^{3}$ Podemos citar, como exemplo, a lei n. 13. 415, de 16 de fevereiro de 2017, que instituiu a Política de Fomento à Implementação de Escolas de Ensino Médio em tempo integral e a lei n. 13.0005, de 25 de junho de 2014 , que aprovou o Plano Nacional de Educacional (PNE) para o decênio $2014-2024$.
} 
Esse raciocínio leva-nos a considerar que a noção de qualidade total em Educação gera um enfraquecimento da autonomia do indivíduo. Decorre dessa situação que o objetivo dos sistemas de ensino passa a ser atingir metas estipuladas pelos parâmetros internacionais de ensino, o que não significa um processo de aprendizado significativo, uma vez que é mais barato treinar estudantes para fazer provas - quando não premiá-los - do que promover o pensamento crítico.

\section{METODOLOGIA}

Este artigo é resultado de pesquisas realizadas durante o 20 semestre de 2016 e 10 semestre de 2017 junto à disciplina de "Currículo e Escola" oferecida pelo curso de licenciatura em Pedagogia da FACLEPP/UNOESTE. A análise metodológica consistiu em levantamento de artigos científicos em bases científicas da Scielo, teses e dissertações de mestrado, debates realizados junto à disciplina e eventos acadêmicos que sustentaram todo o estudo diante da temática (contra) reformas educacionais e (semi) formação de professores. As palavras-chave que nortearam essa investigação foram: (contra) reformas educacionais; políticas públicas; formação de professores.

Como proposta analítica, pautamo-nos em autores filiados à Teoria Crítica da Escola de Frankfurt, os quais forneceram os elementos de crítica para o debate proposto.

\section{RESULTADOS}

As pesquisas realizadas junto à disciplina de Currículo e Escola evidenciaram, no período analisado - segundo semestre de 2016 e primeiro semestre de 2017 - , que as políticas neoliberais propõem uma "nova" concepção de professor, assemelhando-se a um tecnólogo do ensino. Tais observações anunciam a problemática no campo pedagógico: as políticas neoliberais - em consonância com o projeto capitalista internacional - Banco Mundial, FMI - definem as aprendizagens consideradas imprescindíveis para a formação de professores da educação básica, limitando-se ao aspecto das competências e habilidades: que vença o melhor, o mais dedicado, o mais esforçado, o mais competente e o mais produtivo.

Privilegia-se aqui o aspecto do "aprender a aprender constantemente" - um dos pilares da Educação para o século XXI, de acordo com Delors (2012) - desvinculado do "aprender a pensar".

Assim se chega ao tema da crítica aos processos semiculturais atuais.

\section{DISCUSSÃO}

Os argumentos evidenciados anteriormente esclarecem que "a abordagem neoliberal sobre a Educação abandona, portanto, os referenciais da cidadania e da emancipação do sujeito, substituindo-os pela liberdade do consumo educacional à disposição dos clientes" (BUENO, 2003, p. 83).

Tais observações colocam em discussão as estratégias neoliberais para a Educação contemporânea, sustentadas pela perda da dimensão crítica por meio da conversão da Bildung (formação cultural) em Halbbildung (semiformação).

Passemos então ao pensamento de Adorno e Walter Benjamin com relação ao aspecto do depauperamento do pensar na Modernidade. Os argumentos utilizados pelos autores auxiliam em nossa exposição mantendo o objetivo inicial que é o de pensar a prática educativa como uma experiência reflexiva na escola.

Nos escritos filosófico-educacionais, Adorno $(1995,1996)$ aponta que a atual consciência não é apta à experiência. Por estar destituída da possibilidade de experienciar - uma vez que a racionalidade instrumental retirou essa capacidade do indivíduo - essa consciência é caracterizada

\footnotetext{
${ }^{4}$ Adorno, em "Educação - para quê?" apoia-se na argumentação de que a educação deve ultrapassar os aspectos adaptativos, visando a resistência e o inconformismo. Talvez, os quatro pilares da educação definidos por Delors funcionem apenas mais como mecanismos adaptativos a uma sociedade que privilegia a polivalência do que a um processo de resistência aos instrumentos semiculturais.
} 
como coisificada. Disso resulta que a experiência formativa está em baixa, uma vez que, no lugar da experiência, o que se passa é uma experiência substitutiva que, como o próprio nome sugere, substitui precariamente aquela experiência "[...] por um estado informativo pontual, desconectado, intercambiável e efêmero, e que se sabe que ficará borrado no próximo instante por outras informações" (ADORNO, 1996, p. 405).

Diante do exposto, podemos perguntar: o que compõe a experiência em Adorno? Em Adorno (1996) a experiência é viva, se traduz numa abertura ao novo, ao indeterminado, suscita pensamentos, resistências, afetando a consciência do indivíduo de forma profunda.

Na sociedade instrumental e tecnológica, Adorno (1996) afirma que a formação passa a ser mediada pelo princípio da troca, converte-se em mercadoria, em puro fetiche. A consequência imediata da semiformação é a aniquilação do pensamento crítico, pois o "inimigo que se combate é o inimigo que já está derrotado, o sujeito pensante". (ADORNO \& HORKHEIMER, 1985, p. 140). Podemos dizer que o imperativo capitalista submete a formação do indivíduo, ao equivalente de troca, para servir a seus fins. A falta de formação, conclui Adorno (1996), inibe o que ele chama de autorreflexão crítica.

Em Benjamin, a temática da experiência (Erfahrung) ${ }^{5}$, ou melhor, do seu empobrecimento, se torna evidente no ensaio "O narrador", escrito em 1936. Nesse texto, fica exposto o dilema do homem moderno durante a passagem da experiência (Erfahrung) para a vivência (Erlebnis) que valoriza a vida particular do indivíduo em detrimento da vida coletiva que existia até então. Nesse contexto, predomina a solidão em que o homem moderno se torna vítima da civilização urbana e industrial, não conhecendo mais a experiência (Erfahrung) que se baseia na memória de uma tradição cultural e histórica. Resta a esse novo homem que surge da Modernidade a vivência (BENJAMIN, 1994b). É dessa mudança que surge a vivência do choque, vivência essa que empobrece a memória do indivíduo.

Como vimos anteriormente, se não é possível modificar o cenário racional e instrumental, temos então que buscar elementos para fazer dessa pobreza de experiência uma possibilidade de nova experiência através da reflexão e do pensamento crítico.

\section{CONCLUSÃO}

Depois desse rápido percurso analisando o contexto político educacional provocado pelas políticas neoliberais, percebemos que as novas configurações econômicas demarcam novos desafios para a escola. Dessa situação, o primeiro deles refere-se à política de formação docente.

Ao privilegiar apenas a instrumentalização do pensamento e o predomínio de conteúdos e metas a serem atingidas em determinado tempo a um custo mínimo, as políticas neoliberais teriam reduzido a possibilidade de experiências com a cultura nos moldes postulados por Adorno e Walter Benjamin. O depauperamento da escola fica evidente no saber fragmentado, no desprestígio do professor enquanto fonte de conhecimento, nas metodologias reificadoras, no pensamento rígido, nas propostas de reformas cujo objetivo último é qualificar para o mercado de trabalho em que o "aprender a aprender" é desvinculado do "aprender a pensar", na formação instrumental, no sistema de avaliação preocupado apenas em verificar se as metas foram alcançadas - ENEM, SARESP, SAEB, ENADE -, desconsiderando todo o processo de aquisição do conhecimento e da formação do pensamento.

Baseados nas pesquisas por nós realizadas, ressaltamos o modo como o ensino vem se transformando para atender as exigências do mercado de trabalho. Discutimos, neste artigo, o

\footnotetext{
${ }^{5}$ Experiência (Erfahrung) é um termo alemão e significa atravessar uma região durante uma viagem, por lugares desconhecidos. E a sua tradução para o latim - experi - tem como radical per, que significa "perímetro", ou seja, atravessar uma região onde perigos podem nos assaltar. Com o advento da Modernidade, experiência significa prova, demonstração, tentativa, modelo. Essa concepção equivale ao processo de experimentação enquanto método científico que consiste em observar um fenômeno natural, utilizando-se de instrumentos, aparatos, tendo como modelo o cálculo matemático e o funcionamento mecanizado do relógio. Em Adorno e Benjamin, a experiência toma outros sentidos. A experiência é concebida por Benjamin (1989) como uma experiência aberta que se aproxima mais da alegoria por suscitar muitas leituras e inúmeros significados sobre ela. Graças a ela, o presente, o passado e o futuro poderão ser movimentados através da rememoração de tais experiências
} 
modo como a cultura contemporânea se organiza para a busca da eficiência e da eficácia, as quais passaram a ser perseguidas sem maiores considerações quanto à natureza do trabalho escolar, num processo em que valores educacionais foram substituídos por outros de caráter econômico.

Assim, amparados pela análise filosófica de Adorno e Benjamin, o núcleo deste texto aponta para a crítica das políticas neoliberais que, ao privilegiar a meritocracia, a eficácia, a instrumentalização do pensar, contribuem para o depauperamento da experiência na escola.

\section{REFERÊNCIAS}

ADORNO, Theodor \& HORKHEIMER, Max. Dialética do Esclarecimento: fragmentos filosóficos. Tradução de Guido Antônio de Almeida. Rio de Janeiro: Zahar ed., 1985.

ADORNO, Theodor W. Teoria da semicultura. Tradução de Newton Ramos-de-Oliveira; Bruno Pucci; Claudia B. M. Abreu. Educação e sociedade, n o 56, Campinas, São Paulo: Papirus, dez. 1996, p. 388-411.

. Educação... para quê? In: Theodor Adorno: educação e emancipação. Tradução de Wolfgang Leo Maar. Rio de Janeiro: Paz e Terra, 1995, p. 139 - 154.

. Minima Moralia: reflexões a partir da vida danificada. Tradução de Artur Morão. São Paulo: Edições 70, Ltda, 2001.

BENJAMIN, Walter. Experiência e pobreza. In: Obras escolhidas I. Tradução de Sérgio Paulo Rouanet. São Paulo: Brasiliense, 1994a.

. O narrador: considerações sobre a obra de Nikolai Leskov. In: Obras escolhidas I. Tradução de Sergio Paulo Rouanet. São Paulo: Brasiliense, 1994b.

. Obras escolhidas II. Tradução de Sérgio Paulo Rouanet. São Paulo: Brasiliense, 1989.

BRASIL, MEC. Lei n. 9394/96, de 20 de dezembro de 1996. Lei de Diretrizes e Bases da Educação Nacional. Disponível em: http://www.planalto.gov.br/ccivil.leis9394.html. Acesso em 30 jun. 2017. BRASIL. Ministério da Educação. Plano Nacional da Educação (2014 - 2024). Lei n. 13.005. Série Legislação. Congresso Nacional. Brasília, DF: 25 de junho de 2014.

BRASIL. Ministério da Educação. Lei 13.415, de 16 de fevereiro de 2017. Institui a política de fomento à implementação de escolas de ensino médio em tempo integral. Disponível em: http://normaslegais.com.br/legislacao/lei13415-2017.htm. Acesso em: 30 jun. 2017

BUENO, Sinésio F. Pedagogia sem sujeito: qualidade total e neoliberalismo na educação. São Paulo: Annablume/FAPESP, 2003.

CHAUÍ, Marilena. O que é ser educador hoje? Da arte à ciência: a morte do educador. In: Brandão, Carlos (org.). O educador hoje. Rio de Janeiro: Graal, 1982, p. 51 - 70.

DELORS, Jacques. Educação: um tesouro a descobrir. Relatório para a UNESCO da Comissão Internacional sobre Educação para o século XXI. Brasília, DF: Ed. Cortez, MEC/UNESCO, 2012.

FREITAS, L. C. Os reformadores empresariais da educação: da desmoralização do magistério à destruição do sistema público de educação. Educação \& Sociedade, n. 04, 2012, p. 379 - 404. 
LARROSA, Jorge. Notas sobre a experiência e o saber da experiência. Revista Brasileira de Educação, n. 19, São Paulo, jan./abr. 2002, p. 20-28.

OLIVEIRA, Dalila (org.). Reformas educacionais na América Latina e os trabalhadores docentes. Belo Horizonte: Autêntica, 2003.

PARO, Vitor. Administração escolar: introdução crítica. 5ạ Ed. São Paulo: Cortez, 1991.

PUCCl, Bruno. A teoria da semicultura e suas contribuições para a teoria crítica da educação. In: ZUIN, Antônio A. S; PUCCI, Bruno; RAMOS-DE-OLIVEIRA, Newton (orgs.). A educação danificada: contribuições à Teoria Crítica da Educação. Petrópolis, Rio de Janeiro: Vozes, 1997, p. 89 - 116.

SANTANA, Andréia da C. O plano nacional da educação: mais do mesmo. In: MILITÃO, Andréia \& PERBONI, Fábio (orgs.). Plano Nacional de Educação: diversos olhares. 1a Ed. Curitiba, PR: CRV, 2017, p. $79-94$.

SILVA, lara A. As políticas de educação para o ensino médio no Brasil nas últimas décadas do século XX e início do século XXI: o que dizem os documentos e os pesquisadores. MILITÃO, Andréia \& PERBONI, Fábio (orgs.). Plano Nacional de Educação: diversos olhares. 1a Ed. Curitiba, PR: CRV, 2017, p. $186-205$.

SILVA, Tomaz T. Alienígenas na sala de aula: uma introdução aos estudos culturais em educação. Petrópolis: Vozes, 1995. 